\title{
Magnetoresistance in Magnetic Tunnel Junctions With Amorphous Electrodes
}

\author{
Kentaro Nakajima ${ }^{1}$, Gen Feng ${ }^{1}$, and J. M. D. Coey $^{2}$, Member, IEEE \\ ${ }^{1}$ SFI Trinity Nanoscience Laboratory, Physics Department, Trinity College Dublin, Dublin, Ireland \\ ${ }^{2}$ Physics Department, Trinity College Dublin, Dublin, Ireland
}

\begin{abstract}
Magnetic tunnel junctions (MTJs) with amorphous $\mathrm{CoFeB}$ and $\mathrm{Co}_{2} \mathrm{MnSi}$ electrodes were fabricated and examined. In the case of $\left[\mathrm{Co}_{90} \mathrm{Fe}_{10}\right]_{100-x} \mathrm{~B}_{x}$, the $x=32 \%$ boron addition reduces the magnetization by $30 \%$ compared to $\mathrm{Co}_{90} \mathrm{Fe}_{10}$, yet the reduction of the tunnel magnetoresistance (TMR) is over $95 \%$. On the contrary, in the case of $\mathrm{Co}_{(100-x-y)} \mathrm{Mn}_{x} \mathrm{Si}_{y}$, although net magnetization is very small at room temperature, the TMR can be as large as $7 \%$. The character of each metalloid (boron and silicon) could be responsible for the peculiar behavior to each system.
\end{abstract}

Index Terms-Amorphous, MTJ, spin-dependent tunneling.

\section{INTRODUCTION}

$\mathbf{T}$ HE drive for higher tunnel magnetoresistance (TMR) ratio has resulted in the use of novel materials either for the ferromagnetic electrodes or the tunnel barrier. Recently, $70 \%$ of TMR has been observed for $\mathrm{CoFeB}$ electrodes with $\mathrm{Al}$ oxide barrier [1], and over $200 \%$ for $\mathrm{MgO}$ barriers [2], [3]. The magnitude of the TMR is related to the spin polarization of the tunneling electrons. However, the achievement of such high TMR with iron electrodes, which were thought to have a tunneling spin polarization (TSP) of $P \sim 45 \%$, suggests the following: 1) Jullière's model oversimplifies the phenomena; 2) the actual value of TSP depends not only on the density of states near the Fermi level but also on the interface structure and the nature of the spin-dependent conduction channels [4]; and 3) the practical limit on TMR should be established by experiment [5]. In this paper, we examine two different types of amorphous material, namely the $\mathrm{CoFeB}$ and $\mathrm{Co}_{2} \mathrm{MnSi}$ alloys. These materials feature a short mean free path of electrons and lack of long-range order, and in the latter case, the localized magnetic moment is of significance.

\section{EXPERIMENT}

Films were grown in a Shamrock tool by direct current (dc) and radio frequency (RF) magnetron sputtering on glass substrates or thermally oxidized Si substrates. All deposition was carried out at room temperature. In the case of $\mathrm{CoFeB}$ sputtering, we used elemental $\left[\mathrm{Co}_{90} \mathrm{Fe}_{10}\right]_{100-x} \mathrm{~B}_{x}$ targets up to $x=$ $10 \%$ boron content. Further increment of boron content was achieved by placing pure boron pellets on a $\mathrm{Co}_{90} \mathrm{Fe}_{10}$ target. $\mathrm{Co}_{(100-x-y)} \mathrm{Mn}_{x} \mathrm{Si}_{y}$ was fabricated by cosputtering from elemental targets. The sputtering system has six targets arranged in a planetary configuration, and the substrates rotate along with the planetary movement at $44 \mathrm{rpm}$. Film composition was controlled by tuning the sputtering rate of each element individually and checked by energy-dispersive $\mathrm{X}$-ray analysis in a scanning electron microscope. The tunnel barrier was formed by in

Digital Object Identifier 10.1109/TMAG.2005.854717 situ oxidation of an aluminum thin film by $90-240 \mathrm{~s}$ of exposure to oxygen plasma from an inductively coupled plasma coil at 1 mtorr $\mathrm{O}_{2}$ partial pressure and $20 \mathrm{~W}$ RF power. Structural and magnetic characterization was performed using an X-ray diffractometer and a 5-T superconducting quantum interference device (SQUID) magnetometer, respectively.

\section{RESULTS AND DISCUSSION}

\section{A. $\mathrm{CoFeB}$}

Previous studies reported that amorphous $\mathrm{CoFeB}$ electrodes with $x \leq 20 \%$ showed higher TSP than $\mathrm{CoFe}$, although the magnetic moment decreases with the metalloid content. We have made $\left[\mathrm{Cog}_{90} \mathrm{Fe}_{10}\right]_{100-x} \mathrm{~B}_{x}$ films with $2.5<x<60 \%$ with thicknesses ranging from 25 to $50 \mathrm{~nm}$. None of the as-deposited $[\mathrm{Cog} F]_{100-x} \mathrm{~B}$ films show distinct peaks in $\mathrm{X}$-ray diffraction. Fig. 1 shows temperature dependence of TMR for a $\mathrm{Si} / \mathrm{SiO}_{2} / \mathrm{Ta} 20 \mathrm{~nm} /\left[\mathrm{Cog}_{0} \mathrm{Fe}_{10}\right]_{90} \mathrm{~B}_{10} 5 \mathrm{~nm} / \mathrm{Al}$ $(1.4 \mathrm{~nm})-\mathrm{Ox} . /\left[\mathrm{Co}_{90} \mathrm{Fe}_{10}\right]_{90} \mathrm{~B}_{10} 3 \mathrm{~nm} / \mathrm{IrMn} 20 \mathrm{~nm} / \mathrm{Ta} 3 \mathrm{~nm}$ junction. Magnetic resonance (MR) measurements were done on rectangular junctions patterned by photolithography or metal shadow mask techniques. After annealing at $220^{\circ} \mathrm{C}$ for $1 \mathrm{~h}$, the junction shows $51 \%$ TMR at room temperature, and the ratio rises to $69 \%$ at cryogenic temperature. In Fig. 2, we compare the temperature dependence of TMR ratio with that of a junction whose electrodes have higher boron content of 32 $\pm 5 \%$. The boron content of each sample was estimated from grazing incidence X-ray reflectively and density simulation. The junction with $\left[\mathrm{Co}_{90} \mathrm{Fe}_{10}\right]_{68} \mathrm{~B}_{32}$ electrodes shows only $2.5 \%$ TMR ratio at room temperature.

In Fig. 3(a) and (b), we summarize the magnetization of single films and TMR ratios as a function of boron content. The ratios displayed are averages based on 12-24 junctions. Although the magnetization decreases almost linearly as the boron content is increased, the average TMR value rises to $40 \%$ from $30 \%$ for $x=7.5 \%$ and $10 \%$. However, the TMR ratio falls off to $1.5 \%$ for $x=32 \%$. Neither magnetization nor TMR ratio was observed above $x=40 \%$. The reduction of the Curie temperature could be responsible for the disappearance of the TMR above $40 \%$. The reduction of the Curie temperature 


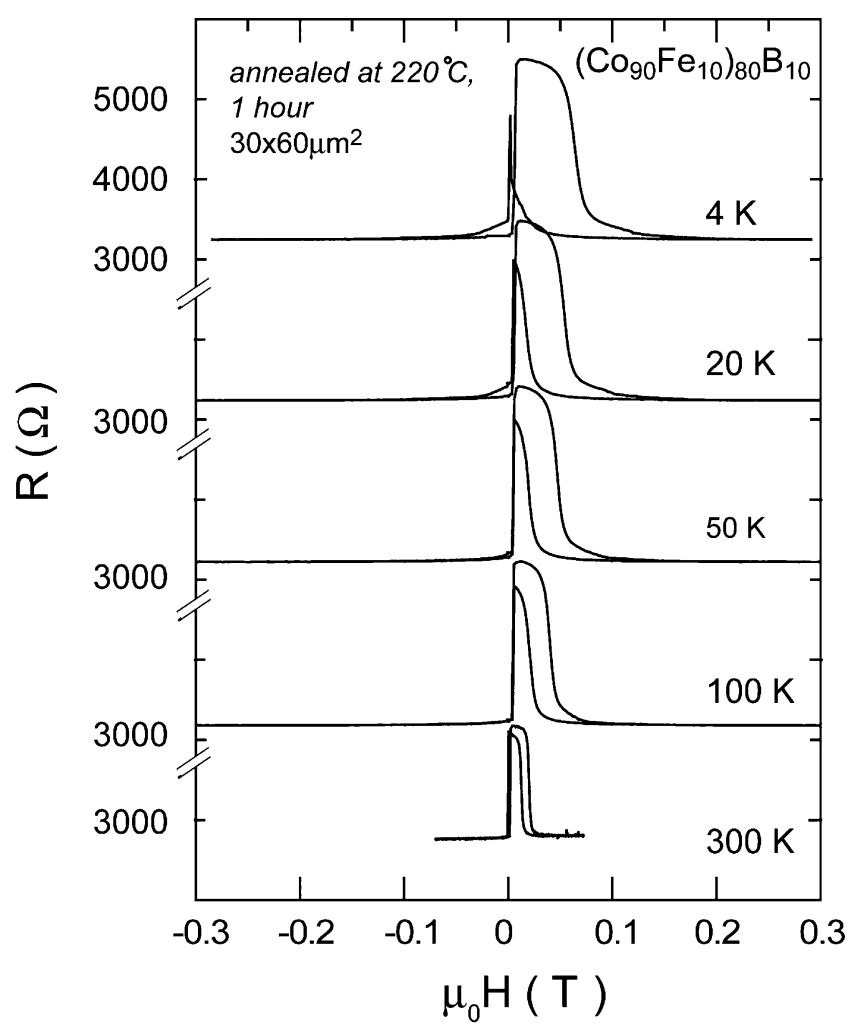

Fig. 1. Temperature dependence of TMR for a $\mathrm{Si} / \mathrm{SiO}_{2} / \mathrm{Ta} /$ $\left[\mathrm{Co}_{90} \mathrm{Fe}_{10}\right]_{90} \mathrm{~B}_{10} 5 \mathrm{~nm} / \mathrm{Al}(1.4 \mathrm{~nm})-\mathrm{Ox} . /\left[\mathrm{Co}_{90} \mathrm{Fe}_{10}\right]_{90} \mathrm{~B}_{10} 3 \mathrm{~nm} / \mathrm{IrMn} / \mathrm{Ta}$ junction.

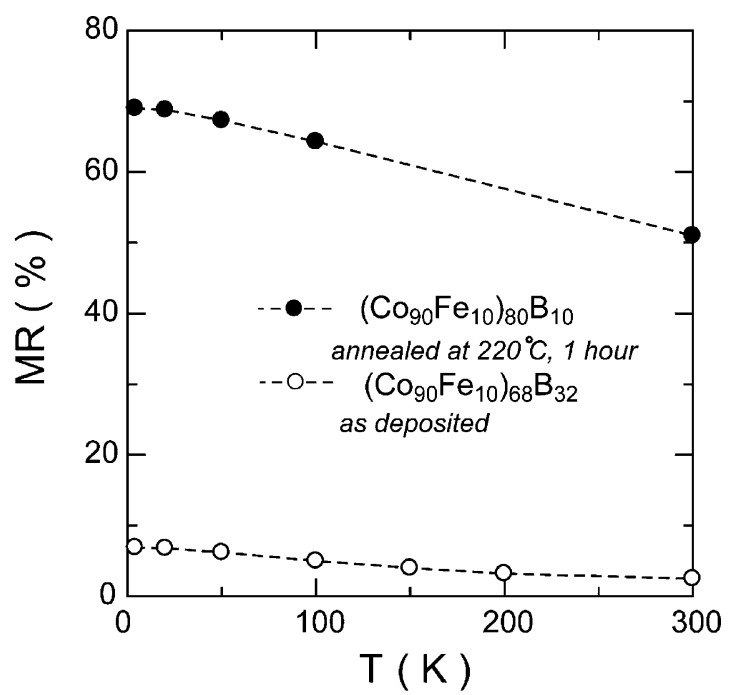

Fig. 2. Temperature dependence of $\mathrm{TMR}$ for a $\mathrm{Si} / \mathrm{SiO}_{2} / \mathrm{Ta} /$ $\left[\mathrm{Co}_{90} \mathrm{Fe}_{10}\right]_{90} \mathrm{~B}_{10} 5 \mathrm{~nm} / \mathrm{Al}(1.4 \mathrm{~nm})-\mathrm{Ox} . /\left[\mathrm{Co}_{90} \mathrm{Fe}_{10}\right]_{90} \mathrm{~B}_{10} 3 \mathrm{~nm} / \mathrm{IrMn} / \mathrm{Ta}$ junction (filled circles) and a $\mathrm{Si} / \mathrm{SiO}_{2} / \mathrm{Ta} /\left[\mathrm{Co}_{90} \mathrm{Fe}_{10}\right]_{68} \mathrm{~B}_{32} 5 \mathrm{~nm} / \mathrm{Al}(1.4$ $\mathrm{nm}$ )-Ox./[C $\left.\mathrm{Co}_{90} \mathrm{Fe}_{10}\right]_{68} \mathrm{~B}_{32} 3 \mathrm{~nm} / \mathrm{IrMn} / \mathrm{Ta}$ junction (open circles).

can be interpreted in terms of the electron transfer from boron atoms to the hole of the cobalt and iron atoms [6]. The reduction of the TSP may be explained by the electron transfer. However, the increase of the TMR observed around $10 \%$ boron content is still an open question.

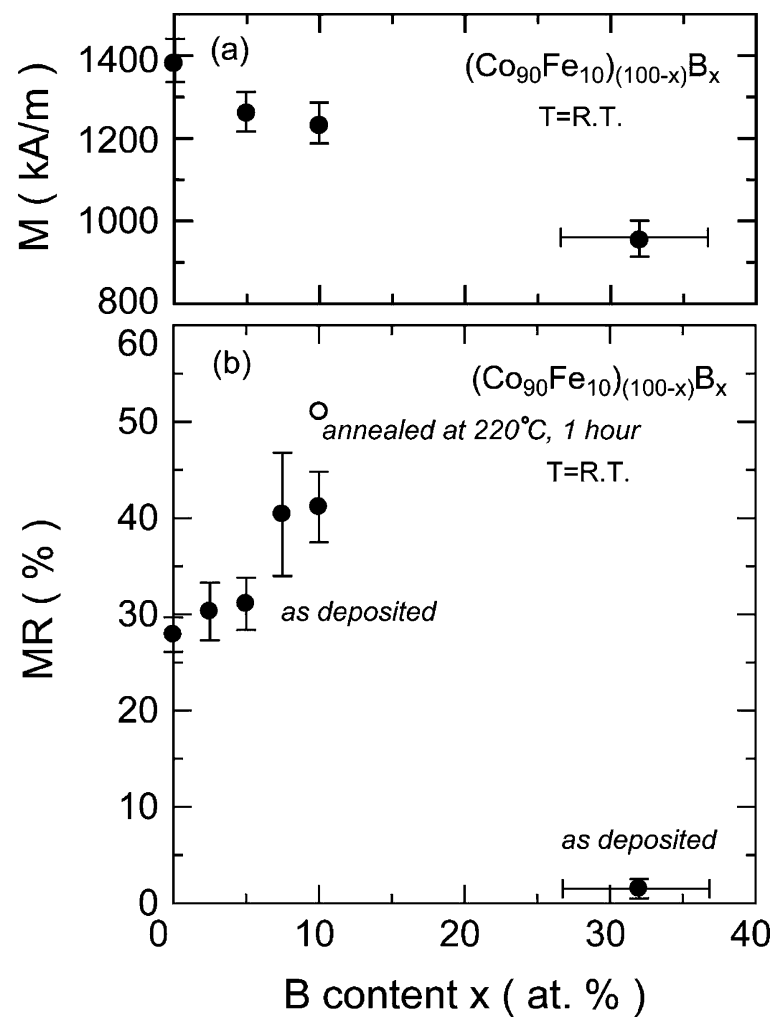

Fig. 3. Boron content dependence of magnetization (a) for single films and (b) TMR for junctions measured at room temperature.
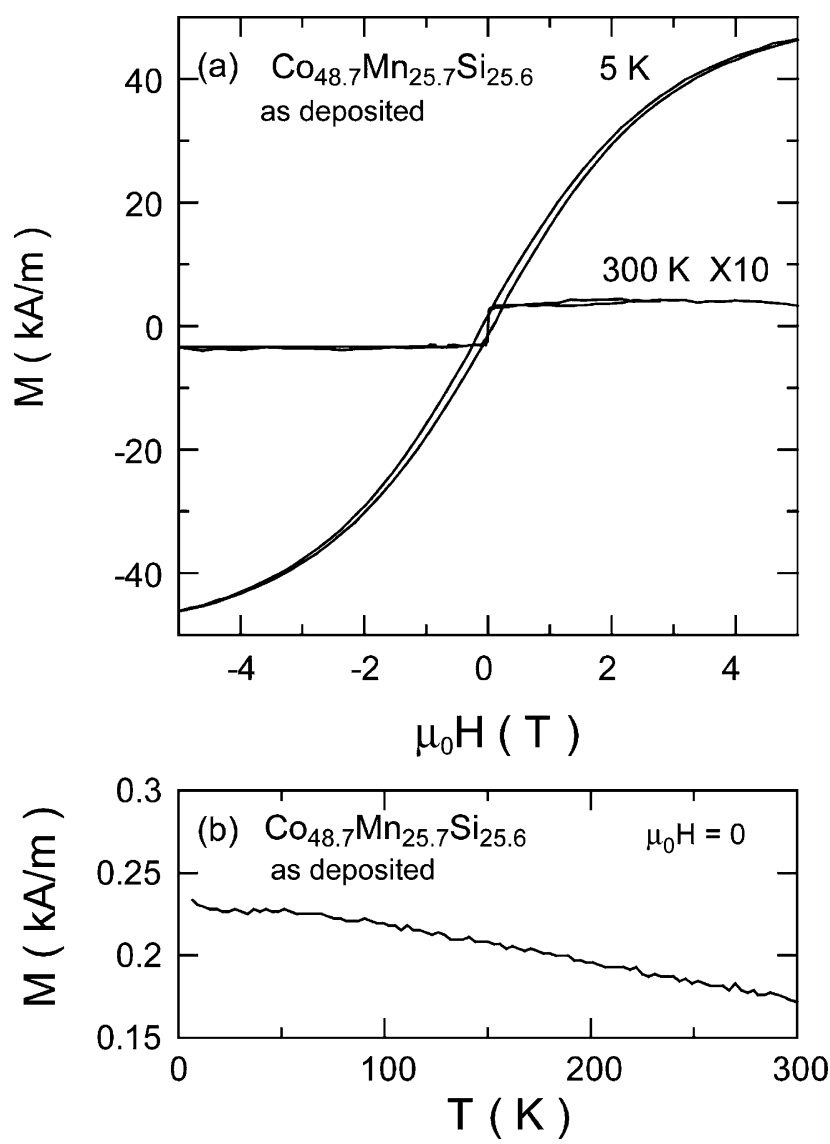

Fig. 4. Temperature dependence of magnetization for an amorphous $\mathrm{Co}_{48.7} \mathrm{Mn}_{25.7} \mathrm{Si}_{25.6}$ film. 

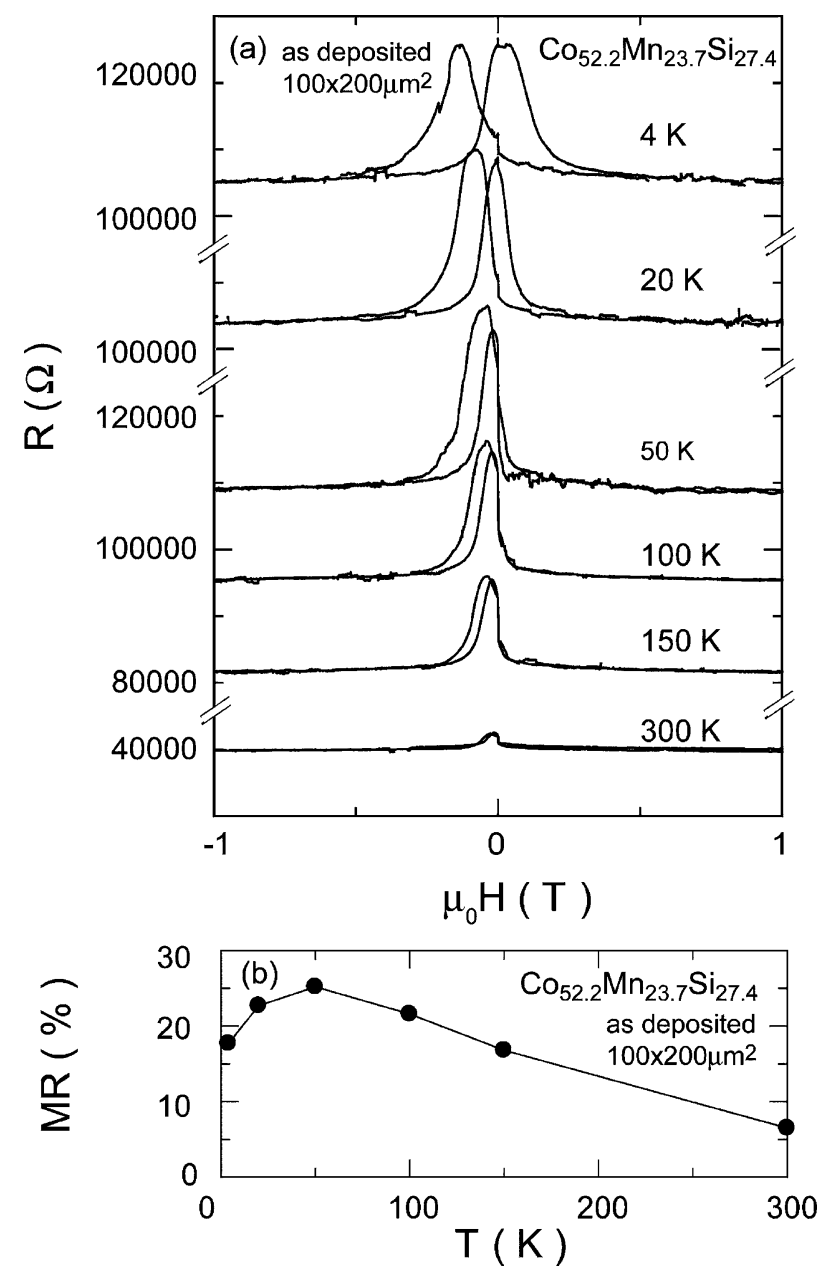

Fig. 5. (a) and (b) Temperature dependence of TMR for $\mathrm{aSi} / \mathrm{SiO}_{2} / \mathrm{amorphous}$ $\mathrm{Co}_{52.2} \mathrm{Mn}_{23.7} \mathrm{Si}_{27.4} 50 \mathrm{~nm} / \mathrm{Al}(1.4 \mathrm{~nm})-\mathrm{Ox} . / \mathrm{Co} / \mathrm{IrMn} / \mathrm{Ta}$ junction.

\section{B. $\mathrm{Co}_{2} \mathrm{MnSi}$}

The other system, $\mathrm{Co}_{2} \mathrm{MnSi}$ is a known Heusler alloy in a cubic lattice. Due to high Si content, however, the alloy can be made amorphous when deposited on a glass substrate at room temperature. We have investigated structural and magnetic properties of $\mathrm{Co}_{(100-x-y)} \mathrm{Mn}_{x} \mathrm{Si}_{y}$ ( $x=18$ to $26, y=23$ to 29) films. Regardless of composition, none of the as-deposited samples show distinct peaks in X-ray diffraction, exhibiting an essentially amorphous phase. After annealing at $500^{\circ} \mathrm{C}$ for $1 \mathrm{~h}$, the films become polycrystalline with a strong (110) texture. Only samples in the narrow range of Si compositions ( $y=25.5$ to 27.8) show both (111) and (200) peaks that correspond to the $\mathrm{L} 22_{1}$ ordered phase. The magnetization of the amorphous $\mathrm{Co}_{48.7} \mathrm{Mn}_{25.7} \mathrm{Si}_{25.6}$ at $5 \mathrm{~T}$ is only $43 \mathrm{kA} / \mathrm{m}$ at $5 \mathrm{~K}$, which falls to less than $0.5 \mathrm{kA} / \mathrm{m}$ at room temperature as shown in Fig. 4(a). The temperature dependence of remanence for the amorphous film is shown in Fig. 4(b), suggesting that the Curie temperature is well over $300 \mathrm{~K}$. The $\mathrm{L} 2{ }_{1}$ ordered film with the same composition shows magnetization of $664 \mathrm{kA} / \mathrm{m}$ at room temperature.

The temperature dependence of TMR for $\mathrm{Si} / \mathrm{SiO}_{2} \mathrm{Ta} 20 \mathrm{~nm} /$ amorphousCo52.2 $\mathrm{Mn}_{23.7} \mathrm{Si}_{27.4} 50 \mathrm{~nm} / \mathrm{Al}$ (1.4 nm)-Ox./Co 3 $\mathrm{nm} / \mathrm{IrMn} 20 \mathrm{~nm} / \mathrm{Ta} 3 \mathrm{~nm}$ junctions is shown in Fig. 5(a) and (b). We have observed a sizable TMR of $7 \%$ at room temperature, although the net magnetic moment is nearly zero. The decline of TMR from 50 to $4 \mathrm{~K}$ can be explained by the deterioration of the separate switching due to the large coercivity of the film. The small net moment at room temperature is explained in terms of antiparallel coupling of the Co and $\mathrm{Mn}$ local moments. A Co-Co nearest-neighbor pair is strongly ferromagnetic, and the $\mathrm{Mn}$ atoms couple antiparallel to their cobalt neighbors [7]. It is, therefore, possible for a material with no net magnetization to exhibit a significant degree of TSP.

\section{CONCLUSION}

The tunneling spin polarization (TSP) in amorphous magnetic tunnel junctions (MTJs) does not reflect the magnitude of the net magnetic moment directly, although it may reflect the spin polarization of conduction electrons in the vicinity of barrier interfaces due to short mean free path and lack of long-range ordering. In the case of $\left[\mathrm{Co}_{90} \mathrm{Fe}_{10}\right]_{100-x} \mathrm{~B}_{x}$, the $x=32 \%$ boron addition reduces the magnetization by $30 \%$ compared to $\mathrm{Cog}_{90} \mathrm{Fe}_{10}$, yet the reduction of the tunnel magnetoresistance (TMR) over 95\%. On the contrary, in the case of $\mathrm{Co}_{(100-x-y)} \mathrm{Mn}_{x} \mathrm{Si}_{y}$, although net magnetization is very small at room temperature, the TMR can be as large as $7 \%$. The character of each metalloid (boron and silicon) could be responsible for the peculiar behavior to each system.

\section{ACKNOWLEDGMENT}

This work was supported by the CINSE project, Science Foundation of Ireland (SFI).

\section{REFERENCES}

[1] D. Wang, C. Nordman, J. M. Daughton, Z. Qian, and J. Fink, “70\% TMR at room temperature for SDT sandwich junctions with $\mathrm{CoFeB}$ as free and reference layers," IEEE Trans. Magn., vol. 40, no. 4, pp. 2269-2271, Jul. 2004.

[2] S. S. P. Parkin, C. Kaiser, A. Panchula, P. M. Rice, B. Hughes, M. Samant, and S.-H. Yang, "Giant tunnelling magnetoresistance at room temperature with $\mathrm{MgO}$ (100) tunnel barriers," Nat. Mater, vol. 3, no. 12, pp. 862-867, 2004.

[3] S. Yuasa, T. Nagahama, A. Fukushima, Y. Suzuki, and K. Ando, "Giant room-temperature magnetoresistance in single-crystal Fe/ $\mathrm{MgO} / \mathrm{Fe}$ magnetic tunnel junctions," Nat. Mater., vol. 3, no. 12, pp. 868-871, 2004.

[4] S. Maekawa and T. Shinjo, Eds., Spin Dependent Transport in Magnetic Nanostructures. London, U.K.: Taylor and Francis, 2002.

[5] M. Coey, "Spin electronics: Thin skins for magnetic sensitivity," Nat. Mater, vol. 4, no. 1, pp. 9-10, 2005.

[6] M. Konč, P. Spišák, P. Kollár, P. Sovák, O. Duša, and T. Reininger, "Temperature dependence of the magnetization and of the other physical properties of rapidly quenched amorphous CoB alloys," IEEE Trans. Magn., vol. 30, no. 2, pp. 524-526, Mar. 1989.

[7] S. Picozzi, A. Continenza, and A. J. Freeman, "Role of structural defects on the half-metallic character of $\mathrm{Co}_{2} \mathrm{MnGe}$ and $\mathrm{Co}_{2} \mathrm{MnSi}$ Heusler alloys," Phys. Rev. B, vol. 69, no. 9, pp. 094 423-1-094 423-7, 2004.

Manuscript received February 7, 2005. 